\title{
Anterior mediastinal large cell neuroendocrine carcinoma with elevated AFP: A case report and review
}

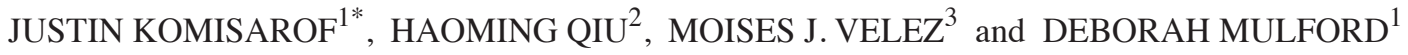 \\ Departments of ${ }^{1}$ Medicine, ${ }^{2}$ Radiation Oncology, ${ }^{3}$ Pathology and Laboratory Medicine, \\ University of Rochester Medical Center, Rochester, NY 14642, USA
}

Received February 6, 2020; Accepted November 18, 2020

DOI: $10.3892 / \mathrm{mco} .2020 .2196$

\begin{abstract}
Large cell neuroendocrine carcinoma (LCNEC) is a rare and aggressive cancer that typically presents in the lung. The current case report describes a 56 year old male who presented to Strong Memorial Hospital with progressive dyspnea and was revealed to have a large anterior mediastinal tumor with metastases to axillary, hilar and mediastinal lymph nodes. Tumor marker results revealed an elevated plasma level of $\alpha$-fetoprotein (AFP), which initially pointed towards a diagnosis of teratoma, but the tumor stained positive for neuroendocrine markers CD56, chromogranin, and synaptophysin on biopsy, consistent with LCNEC. AFP-positive tumor cells were identified, and no alternate cause for the elevated AFP was identified. The patient underwent genetic testing revealing the tumor to be ALK, ROS1, KRAS, BRAF and EGFR wild type. The patient received 6 cycles of chemotherapy with cisplatin $\left(80 \mathrm{mg} / \mathrm{m}^{2}\right)$ and etoposide $\left(100 \mathrm{mg} / \mathrm{m}^{2}\right)$ and then radiation with an initial minor response. The patients course was complicated by the development of superior vena cava syndrome requiring emergency stenting. The results of the current case suggest that AFP may be worthy of further exploration as a potential tumor marker in LCNEC.
\end{abstract}

\section{Introduction}

Large cell neuroendocrine carcinoma (LCNEC) is a high-grade neoplasm most commonly presenting in the lung, although it has been noted in the literature to occasionally arise in other locations including the gastrointestinal tract, bladder, prostate, gallbladder, ovary, uterus and submandibular gland (1-7). LCNEC is a rare cancer, estimated to comprise between 2.1 and $3.5 \%$ of surgically resected lung tumors $(8,9)$. It is morphologically different from small cell lung cancer (SCLC) and has a higher mitotic

Correspondence to: Dr Justin Komisarof, Department of Medicine, University of Rochester Medical Center, 601 Elmwood Avenue, Box MED, Rochester, NY 14642, USA

E-mail: Justin_komisarof@urmc.rochester.edu

Key words: large-cell neuroendocrine carcinoma, mediastinal tumor, anterior mediastinum, case report, $\alpha$-fetoprotein, chemoradiation, small cell lung cancer count than low-grade neuroendocrine carcinoma (10-12). These tumors have unique histological features including large nuclei with prominent nucleoli, vesicular or open chromatin, rosette-like structures, and trabecular palisading patterns (13). When a diagnosis of LCNEC cannot be made on a morphological basis, immunohistochemical markers exist that can differentiate the disease from SCLC (14). A strong association between LCNEC and cigarette smoking has been documented $(8,9,15)$. Unfortunately, prognosis for LCNEC is generally poor, with a 5-year all-stage survival rate of about $40 \%$ (16).

Investigations into the LCNEC genome via next-generation sequencing have found that the cancer clusters into two different groups, a SCLC-like subset and a NSCLC-like subset $(17,18)$. There is no morphological difference between tumor cells belonging to either subset; however, the SCLC-like tumors tend to have higher proliferative activity (18). SCLC-like LCNEC tumors are characterized by inactivating mutations in TP53 and RB1, while NSCLC-like LCNEC has frequent mutations in STK11 (60\%), KRAS (40\%), and KEAP1 (36\%) (18). Mutations in PIK3CA (3\%), PTEN (4\%), and FGFR (5\%) are uncommon in LCNEC (19), and mutations for which targeted therapy exists, including EGFR, BRAF and ALK, are very unusual $(<1 \%)(13,17,19)$.

Due to the relative rarity of LCNEC, no large-scale randomized controlled trials have been conducted and no standardized treatment regimen has been established as clearly superior. It is well-established that surgical resection is the only curative treatment modality and that adjuvant chemotherapy appears to confer a survival benefit (20). Thoracic radiotherapy (RT) also appears to show a survival benefit when combined with chemotherapy (21). Most patients are not surgical candidates (22), and typically are treated with chemotherapy regimens similar to those used for small cell lung carcinoma, most often platinum and etoposide. However, studies have not conclusively demonstrated the superiority of this regimen over platinum and gemcitabine chemotherapy regimens used for non-small cell lung cancer $(23,24)$. Targeted therapy has been used against these tumors, but LCNEC rarely harbors targetable mutations $(13,17,25)$. In the future, the incorporation of molecular data may ultimately impact treatment decisions and patient outcomes by identifying an optimal, personalized treatment regimen for a tumor's specific molecular makeup. In one study, patients found to be wild-type for RB1 had significantly longer survival when treated with gemcitabine and a 


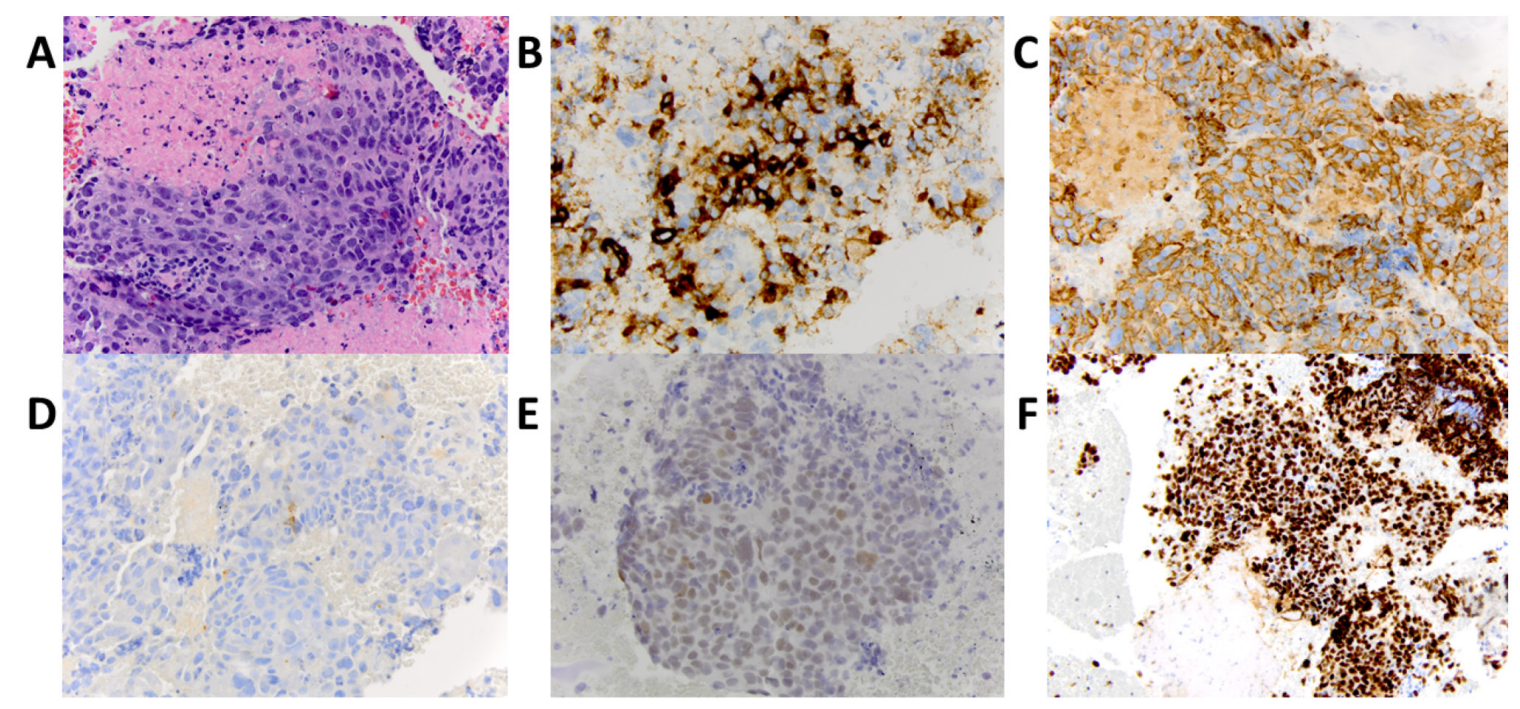

Figure 1. Immunohistochemical staining of tumor. (A) Chromogranin staining, magnification, x40. (B) Hematoxylin and Eosin staining, magnification, $x$ 40. (C) Pancytokeratin staining, magnification, x40. (D) AFP staining, magnification, x40. (E) SALL4 staining, magnification, x40. (F) Ki67 staining, magnification, $\mathrm{x} 20$. AFP, $\alpha$-fetoprotein.

taxane than those treated with cisplatin/etoposide (26). Loss of P16 expression was also predictive of superior survival with gem/taxane chemotherapy (26).

\section{Case report}

A 56 year old male presented to the hospital after a month of progressive dyspnea. He attested to significant weight loss over the past 6 months and had also developed a cough with occasional hemoptysis. He was an active smoker, having smoked a pack of cigarettes a day for the past 20 years. He had been experiencing intermittent chest pain, but denied any fevers, chills, or night sweats. All initial laboratory data were unremarkable. A chest X-ray taken in the emergency department revealed a large perihilar opacity and follow-up chest computed tomography (CT) demonstrated a 7.9x8.5 cm right-sided anterior mediastinal mass with left tracheal deviation. The mass encased the superior vena cava (SVC) and right bronchus but both structures were patent. Tumor marker labs revealed an elevated lactate dehydrogenase (254 U/l) and an increased level $(158 \mathrm{IU} / \mathrm{ml})$ of $\alpha$-fetoprotein (AFP), suggestive initially of teratoma. B-hCG was undetectable. The tumor was biopsied via endobronchial ultrasound (EBUS) guided bronchoscopy, which revealed sheets of large cells with eosinophilic cytoplasm, enlarged nuclei, and prominent nucleoli (Fig. 1A). Necrosis, apoptotic bodies and conspicuous mitotic activity was present. Immunohistochemical studies were performed on the Dako Omnis (Agilent) platform using a polymer detection method, utilizing horseradish peroxidase substrate 3,3'-diaminobenzidine tetrahydrochloride (DAB) for visualization. The tumor cells showed immunohistochemical positivity for pancytokeratin, chromogranin, synaptophysin and CD56. Rare cells showed cytoplasmic positivity for AFP (Fig. 1B-D). SALL4 showed patchy and weak nuclear positivity (Fig. 1E). Ki67 (MIB-1) showed an elevated proliferative index of over $95 \%$ (Fig. 1F). The tumor cells did not stain with TTF-1, napsin A, p40, CD30, OCT3/4 or PLAP. The findings were consistent with LCNEC. Follow-up staging with positron emission tomography (PET) revealed hypermetabolic mediastinal, right hilar, and left axillary lymph nodes (non-regional lymphadenopathy) suggestive of metastasis, making this stage IV (Fig. 2). Molecular studies performed on the biopsy tissue revealed the tumor to be ALK, ROS1, KRAS, BRAF and EGFR wild type. PD-L1 (clone 22C3) expression was $3 \%$. The biopsy tissue stained negative for AFP. The patient was not a surgical candidate and was started on a palliative chemotherapy regimen of cisplatin $\left(80 \mathrm{mg} / \mathrm{m}^{2}\right)$ and etoposide $\left(100 \mathrm{mg} / \mathrm{m}^{2}\right)$. He completed five cycles of cisplatin/etoposide, with a dose reduction on the fifth cycle due to anemia. A follow-up CT scan after the second cycle of chemotherapy revealed interval decrease in size of the mediastinal mass to $7.0 \times 7.6 \mathrm{~cm}$, however AFP had almost doubled in this time to $267 \mathrm{IU} / \mathrm{ml}$ (Fig. 3). Another follow-up CT scan at the time of his last cycle revealed interval development of a $3.2 \mathrm{~cm}$ right upper lobe mass. AFP was now $392 \mathrm{IU} / \mathrm{ml}$. He was recommended to undergo palliative radiotherapy. No concomitant chemotherapy was administered during this period. He received 15 fractions of external beam RT to the mediastinal mass totaling $37.5 \mathrm{~Gy}$. AFP measured at the conclusion of radiotherapy was $161 \mathrm{IU} / \mathrm{ml}$. Follow-up CT scan 2 months after conclusion of radiotherapy revealed the mediastinal mass to be roughly unchanged in size at $6.8 \times 8.2 \mathrm{~cm}$. A moderate size right pulmonary effusion was noted and the SVC was also noted to be completely occluded. The patient underwent thoracentesis and no malignant cells were detected within the thoracentesis sample. The SVC was recanalized and stented successfully by interventional radiology (Fig. 4). Several months after this incident he experienced a rapid decline in functional status and passed away.

\section{Discussion}

LCNEC is a rare form of cancer most frequently seen in the lung. Here, we report a case of LCNEC presenting in the anterior mediastinum associated with elevated AFP, which has only been reported in the literature once before (27). The 

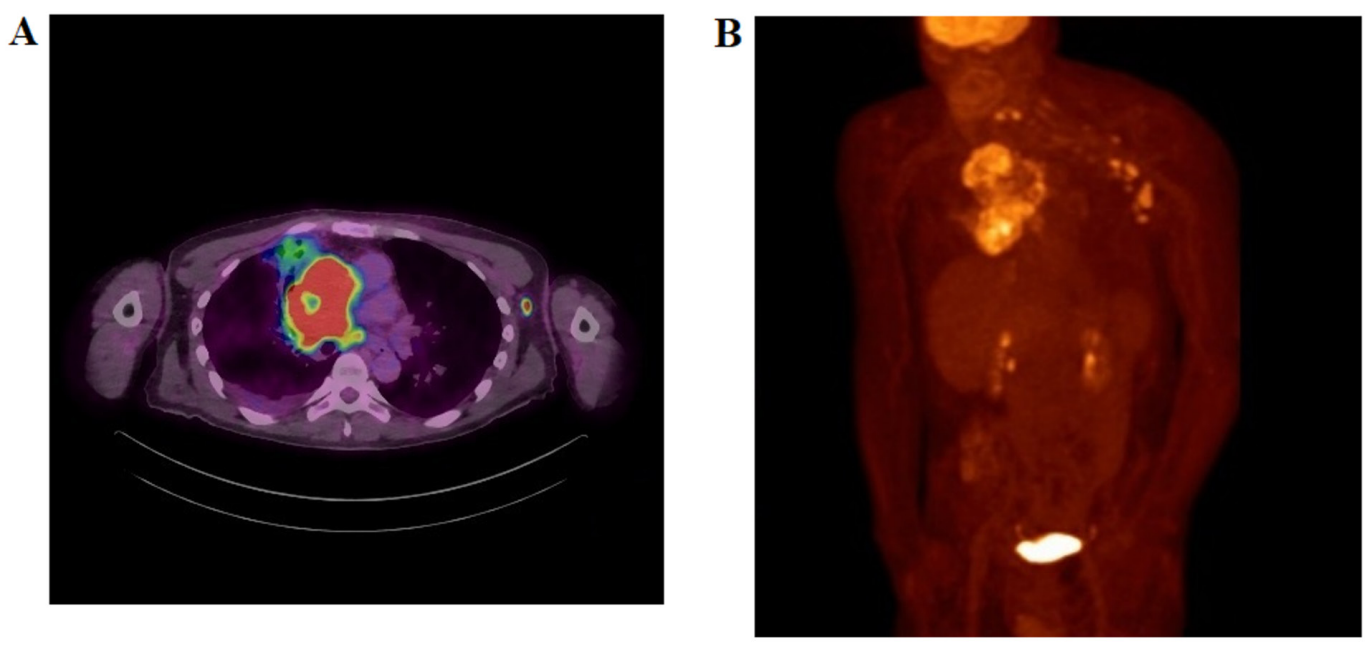

Figure 2. Initial staging of anterior mediastinal mass, PET/CT. (A) Axial view. Hypermetabolic left axillary lymph node is also visible. (B) Transverse view. Multiple subcarinal and left axillary hypermetabolic lymph nodes are visible.

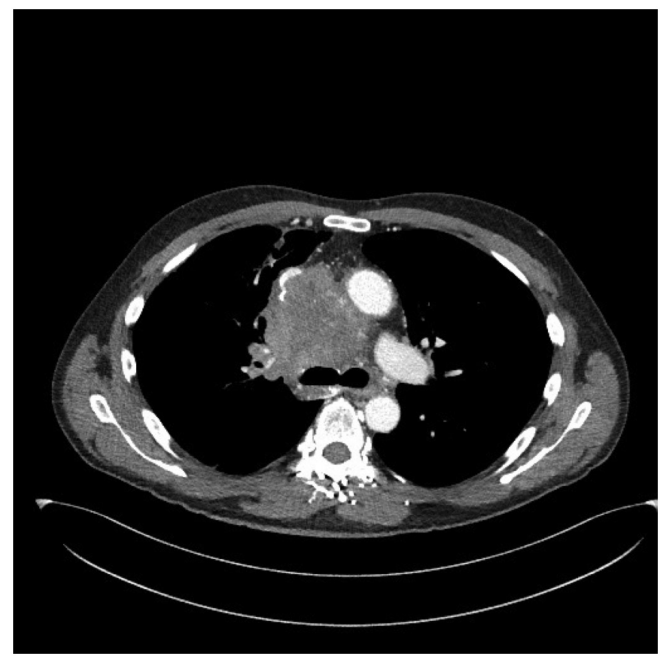

Figure 3. Response to initial chemoradiation, CT chest. Tumor dimensions diminished to $7.0 \times 7.6 \mathrm{~cm}$.

differential for this tumor included lung adenocarcinoma extending into the mediastinum, SCLC, and other tumors of the anterior mediastinum: Thymoma, thymic carcinoma, lymphoma, and teratoma $(28,29)$. Our patient was initially suspected to have a teratoma as these tumors have been known to present as a large mediastinal tumor with elevated AFP (30). His tumor was initially marginally responsive to standard SCLC cisplatin/etoposide chemotherapy, but then the disease quickly progressed on this regimen with development of a new lung mass. In a previous study, $73 \%$ of LCNEC patients treated with cisplatin/etoposide achieved at least a partial response, defined as a $30 \%$ reduction in the sum of tumor diameters (23). Our patient unfortunately did not achieve even this partial response, which could have been due to the size of the tumor at the onset of therapy, or the inability of the patient to complete the full course of chemotherapy.

AFP is known to be a valuable tumor marker in hepatocellular carcinoma (HCC) to evaluate response to chemotherapy and radiotherapy (31). In this case, the patient's disease progressed while on chemotherapy, associated with a
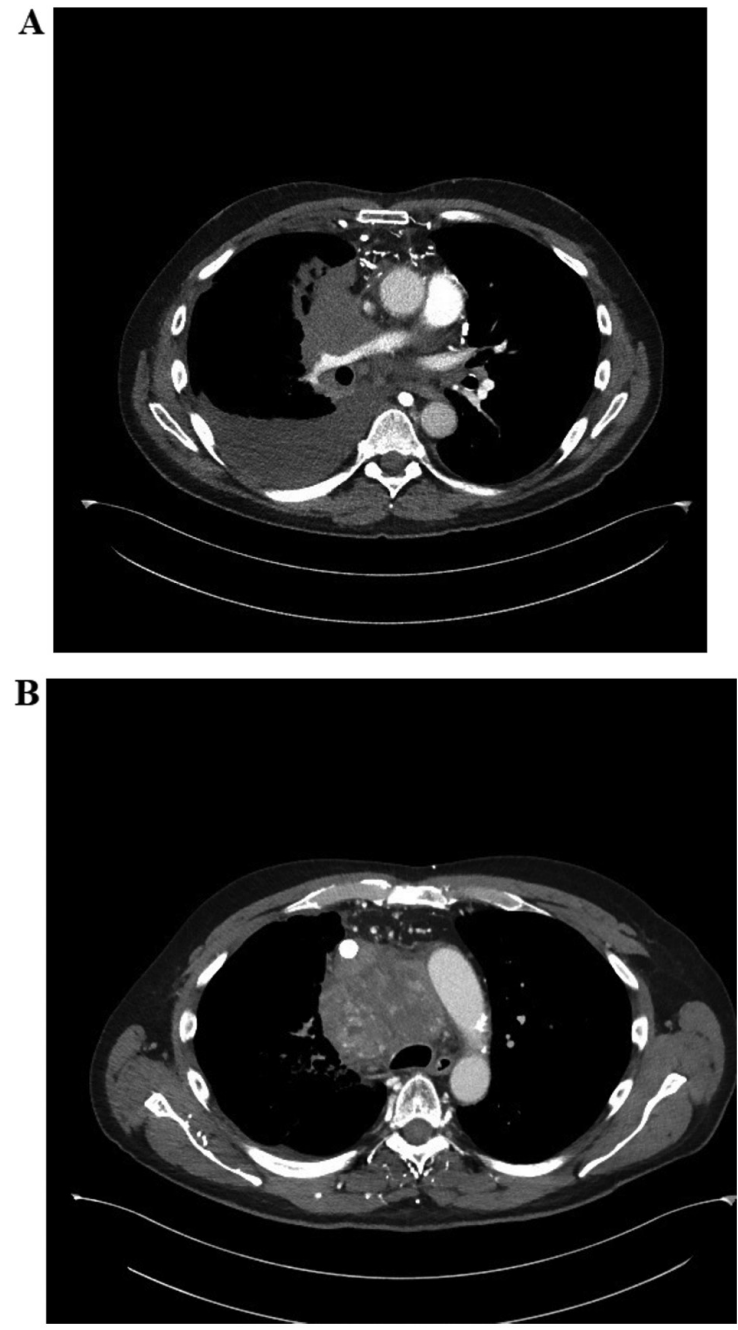

Figure 4. SVC occlusion and stenting, CT chest. (A) Complete occlusion of the SVC. (B) Successful stenting of the SVC with clinical improvement in SVC syndrome. SVC, superior vena cava.

significant rise in AFP. After receiving palliative radiotherapy to the mediastinal mass, AFP decreased and the patient's disease was stable for some time. While the biopsy sample 
did not stain positive for AFP, these tumors are known to be heterogenous and this does not rule out the possibility that a portion of the mass that was not captured by biopsy was producing AFP. The patient did not have HCC or a germ-cell tumor that could have been responsible for this elevated AFP. These findings suggest that the use of AFP as a tumor marker for some LCNECs may be worthy of future exploration.

\section{Acknowledgements}

Not applicable.

\section{Funding}

No funding was received.

\section{Availability of data and materials}

Data sharing is not applicable to this article, as no datasets were generated or analyzed during the current study.

\section{Authors' contributions}

JK and DM wrote the manuscript. DM was the patient's primary medical oncologist. MJV performed immunohistochemical staining. HQ was the patient's primary radiation oncologist and helped generate figures. All authors read and approved the final manuscript.

\section{Ethics approval and consent to participate}

Not applicable.

\section{Patient consent for publication}

Written consent was unobtainable as the patient passed away prior to publication and it was not possible to contact next of kin. The IRB of the University of Rochester reviewed this work and confirmed that there is no identifying information and that there are significant public interest considerations in the publication of this work.

\section{Competing interests}

The authors declare that they have no competing interests.

\section{References}

1. Buscemi S, Orlando E, Damiano G, Portelli F, Palumbo VD, Valentino A, Marrazzo A, Buscemi G and Lo Monte AI: 'Pure' large cell neuroendocrine carcinoma of the gallbladder. Report of a case and review of the literature. Int J Surg 28 (Suppl 1): S128-S132, 2016.

2. Radović N, Turner R and Bacalja J: Primary 'pure' large cell neuroendocrine carcinoma of the urinary bladder: A case report and review of the literature. Clin Genitourin Cancer 13: e375-e377, 2015.

3. Okoye E, Choi EK, Divatia M, Miles BJ, Ayala AG and Ro JY: De novo large cell neuroendocrine carcinoma of the prostate gland with pelvic lymph node metastasis: A case report with review of literature. Int J Clin Exp Pathol 7: 9061-9066, 2014.

4. Ki EY, Park JS, Lee KH, Bae SN and Hur SY: Large cell neuroendocrine carcinoma of the ovary: A case report and a brief review of the literature. World J Surg Oncol 12: 314, 2014.
5. Kawaratani H, Tsujimoto T, Yoshikawa M, Kawanami F, Shirai Y, Yoshiji H, Morita K and Fukui H: Large cell neuroendocrine carcinoma presenting with neck swelling in the submandibular gland: A case report. J Med Case Rep 7: 81, 2013.

6. Ogura J, Adachi Y, Yasumoto K, Okamura A, Nonogaki H, Kakui K, Yamanoi K, Suginami K, Koyama T and Ikehara S: Large-cell neuroendocrine carcinoma arising in the endometrium: A case report. Mol Clin Oncol 8: 575-578, 2018.

7. Kobayashi A, Yahata T, Nanjo S, Mizoguchi M, Yamamoto M, Mabuchi Y, Yagi S, Minami S and Ino K: Rapidly progressing large-cell neuroendocrine carcinoma arising from the uterine corpus: A case report and review of the literature. Mol Clin Oncol 6: 881-885, 2017.

8. Gu J, Gong D, Wang Y, Chi B, Zhang J, Hu S and Min L: The demographic and treatment options for patients with large cell neuroendocrine carcinoma of the lung. Cancer Med 8: 2979-2993, 2019.

9. Naidoo J, Santos-Zabala ML, Iyriboz T, Woo KM, Sima CS, Fiore JJ, Kris MG, Riely GJ, Lito P, Iqbal A, et al: Large Cell neuroendocrine carcinoma of the lung: Clinico-pathologic features, treatment, and outcomes. Clin Lung Cancer 17: e121-e129, 2016.

10. Gollard R, Jhatakia S, Elliott $M$ and Kosty M: Large cell/neuroendocrine carcinoma. Lung Cancer 69: 13-18, 2010.

11. Xuan WX, Li JJ, Shi YJ and Zhang XJ: Atypical carcinoid: A rare finding of a man with mediastinal mass: A case report. Mol Clin Oncol 12: 325-328, 2020.

12. Melosky B: Advanced typical and atypical carcinoid tumours of the lung: Management recommendations. Curr Oncol 25 (Suppl 1): S86-S93, 2018.

13. Hiroshima K and Mino-Kenudson M: Update on large cell neuroendocrine carcinoma. Transl Lung Cancer Res 6: 530-539, 2017.

14. Bari MF, Brown H, Nicholson AG, Kerr KM, Gosney JR, Wallace WA, Soomro I, Muller S, Peat D, Moore JD, et al: BAI3, CDX2 and VIL1: A panel of three antibodies to distinguish small cell from large cell neuroendocrine lung carcinomas. Histopathology 64: 547-556, 2014.

15. Filosso PL, Rena O, Guerrera F, Moreno Casado P, Sagan D, Raveglia F, Brunelli A, Welter S, Gust L, Pompili C, et al: Clinical management of atypical carcinoid and large-cell neuroendocrine carcinoma: A multicentre study on behalf of the European Association of Thoracic Surgeons (ESTS) neuroendocrine tumours of the lung working group. Eur J Cardiothorac Surg 48: 55-64, 2015.

16. Asamura H, Kameya T, Matsuno Y, Noguchi M, Tada H, Ishikawa Y, Yokose T, Jiang SX, Inoue T, Nakagawa K, et al: Neuroendocrine neoplasms of the lung: A prognostic spectrum. J Clin Oncol 24: 70-76, 2006.

17. Rossi G, Bertero L, Marchiò C and Papotti M: Molecular alterations of neuroendocrine tumours of the lung. Histopathology 72 : $142-152,2018$

18. Rekhtman N, Pietanza MC, Hellmann MD, Naidoo J, Arora A, Won H, Halpenny DF, Wang H, Tian SK, Litvak AM, et al: Next-generation sequencing of pulmonary large cell neuroendocrine carcinoma reveals small cell carcinoma-like and non-small cell carcinoma-like subsets. Clin Cancer Res 22: 3618-3629, 2016.

19. Miyoshi T, Umemura S, Matsumura Y, Mimaki S, Tada S, Makinoshima H, Ishii G, Udagawa $\mathrm{H}$, Matsumoto S, Yoh K, et al: Genomic profiling of large-cell neuroendocrine carcinoma of the lung. Clin Cancer Res 23: 757-765, 2017.

20. Filosso PL, Guerrera F, Evangelista A, Galassi C, Welter S, Rendina EA, Travis W, Lim E, Sarkaria I, Thomas PA, et al: Adjuvant chemotherapy for large-cell neuroendocrine lung carcinoma: Results from the European Society for Thoracic Surgeons Lung Neuroendocrine Tumours Retrospective Database. Eur J Cardiothorac Surg 52: 339-345, 2017.

21. Prelaj A, Rebuzzi SE, Del Bene G, Giròn Berrìos JR, Emiliani A, De Filippis L, Prete AA, Pecorari S, Manna G, Ferrara C, et al: Evaluation of the efficacy of cisplatin-etoposide and the role of thoracic radiotherapy and prophylactic cranial irradiation in LCNEC. ERJ Open Res 3: 00128-2016, 2017.

22. Cao L, Zhao L, Wang M, Zhang XH, Yang ZC and Liu YP: Clinicopathological characteristics and prognosis of pulmonary large cell neuroendocrine carcinoma aged 65 years. PeerJ 7: e6824, 2019.

23. Sun JM, Ahn MJ, Ahn JS, Um SW, Kim H, Kim HK, Choi YS, Han J, Kim J, Kwon OJ, et al: Chemotherapy for pulmonary large cell neuroendocrine carcinoma: Similar to that for small cell lung cancer or non-small cell lung cancer? Lung Cancer 77: 365-370, 2012. 
24. Rieber J, Schmitt J, Warth A, Muley T, Kappes J, Eichhorn F, Hoffmann H, Heussel CP, Welzel T, Debus J, et al: Outcome and prognostic factors of multimodal therapy for pulmonary large-cell neuroendocrine carcinomas. Eur J Med Res 20: 64, 2015.

25. Daido W, Yamasaki M, Saito N, Ishiyama S, Deguchi N, Taniwaki M, Daga $\mathrm{H}$ and Ohashi N: Effectiveness of nivolumab in large-cell neuroendocrine carcinoma of the lung-A report of two cases. Gan To Kagaku Ryoho 44: 59-62, 2017 (In Japanese).

26. Derks JL, Leblay N, Thunnissen E, van Suylen RJ, den Bakker M, Groen HJM, Smit EF, Damhuis R, van den Broek EC, Charbrier A, et al: Molecular subtypes of pulmonary large-cell neuroendocrine carcinoma predict chemotherapy treatment outcome. Clin Cancer Res 24: 33-42, 2018.

27. Takezawa K, Okamoto I, Fukuoka J, Tanaka K, Kaneda H, Uejima $\mathrm{H}$, Yoon HE, Imakita M, Fukuoka $\mathrm{M}$ and Nakagawa $\mathrm{K}$ : Large cell neuroendocrine carcinoma of the mediastinum with alpha-fetoprotein production. J Thorac Oncol 3: 187-189, 2008.
28. Juanpere S, Cañete N, Ortuño P, Martínez S, Sanchez G and Bernado L: A diagnostic approach to the mediastinal masses. Insights Imaging 4: 29-52, 2013.

29. Almeida PT and Heller D: Anterior Mediastinal Mass. In: StatPearls (Internet). Available from: https://www.ncbi.nlm. nih.gov/books/NBK546608/.

30. Yendamuri S: Resection of a giant mediastinal teratoma. Ann Thorac Surg 102: e401-e402, 2016.

31. Sanchez AIP, Roces LV, Garcia IZ, Lopez EL, Hernandez MAC, Parejo MIB and Pena-Diaz J: Value of $\alpha$-fetoprotein as an early biomarker for treatment response to sorafenib therapy in advanced hepatocellular carcinoma. Oncol Lett 15: 8863-8870, 2018.

This work is licensed under a Creative Commons Attribution-NonCommercial-NoDerivatives 4.0 International (CC BY-NC-ND 4.0) License. 